\title{
A FATALIDADE DO DESEJO \\ Senhora dos afogados, de Nelson Rodrigues
}

\author{
Leda Maria Martins \\ UFMG
}

\begin{abstract}
RESUMO
Neste texto abordo a reconfiguração da noção de hamartia, a falha trágica, em Senhora dos afogados, de Nelson Rodrigues, tomando como referência a personagem Moema.
\end{abstract}

\author{
PALAVRAS-CHAVE \\ hamartia, fatalidade, Senhora dos afogados
}

Los papeles póstumos son semejantes a unas ruinas, ¿y qué refugio hay más natural que éste para unos sepultados? $\mathrm{El}$ arte, pues, consiste en producir artisticamente la misma impresión, el mesmo desaliño e interinidad, y el mismo pensamiento anacoluto que son característicos de ese lugar desamparado. El arte está en producir un gozo que en ningún caso sea del momento presente, sino que entrañe siempre algo esencial del tiempo pasado, algo que así sea presente en el tiempo pasado.

Kierkegaard

$\mathrm{E}_{\mathrm{m}}$ Nelson Rodrigues, a matéria dramática é extraída dos afetos e, principalmente, dos sentimentos que os manifestam. Ácidos, tenebrosos, excessivos, os sentimentos se coisificam nas personagens, contorcidos numa arquitetura cênica que, freqüentemente, abole a atitude mimética especular, para se mostrar como ato interpretativo: em Nelson, o teatro é uma metonímia da polis, lugar no qual a natureza humana se vê representada e se representa, desnudando, dramaticamente, aos próprios olhos, as múltiplas facetas de sua ilusória integridade e de seu tênue equilíbrio. $O$ teatro, assim concebido, tornase, em Nelson, ato do inconsciente.

Esse teatro dos afetos é movido por uma mola avassaladora, a fatalidade das pulsōes mais íntimas que recobrem as ações dos sujeitos ali encenados:

A maioria dos protagonistas de Nelson suporta uma carga de aniquilamento que os aproxima do herói expressionista. Na tragédia grega, pesa sobre o indivíduo uma fatalidade que o faz passar de um estado bom inicial a um estada mau final. Abatese sobre ele o Destino, brincando ironicamente com as ilusões da aventura terrestre. (...)

O herói expressionista tem com o trágico o parentesco da fatalidade, que o abate irremediavelmente. Apenas, a fatalidade vem do íntimo, força avassaladora que o arrasta para o abismo (é bem essa a realidade, não recurso de expressão). $O$ homem 
carrega dentro de si demônios que, se liberados, o perdem para sempre. A vida arrasta-se em equilíbrio instável, até que, acionada a fera que habita nele, dominao a vertigem do aniquilamento.

No entanto, essa noção de fatalidade que se adere às tramas rodrigueanas mantém, como leitmotif, uma relação dissonante com o papel da moira na tragédia grega clássica. A noção grega do trágico ressoa em Nelson por um uso muito particular de elementos cênicos e dramáticos da matriz ática, por ele reinterpretada em alusões periféricas. Assim, se o drama grego buscava nos mitos arcaicos, conhecidos e reconhecíveis, o conteúdo exemplar da convenção formal trágica, Nelson faz ressoar nos conflitos das subjetividades e das relações afetivas, na contemporaneidade, ecos de uma substância atemporal e material própria do sujeito, em qualquer época. Transcriados por elementos da linguagem cênica (coros, máscaras, artifícios verbais, etc), pela composição de motivações e elaboração de intrigas, pelo predomínio da teatralidade e pelo vigor da palavra em diálogo, esses ecos do trágico, como cosmovisão e forma, são recursos que Nelson insistentemente reativa, num esforço não de reduplicação especular da forma, mas, sim, de realçamento da cena fingida do palco como lugar de uma pulsão do drama humano. Do trágico, Nelson busca a idéia de um sentido para o humano, sentido este que, tanto na tragédia grega quanto no drama contemporâneo, é a matéria que traduziria, para o dramaturgo, a natureza ainda primária e arcaica da subjetividade.

Como afirma Angela Leite Lopes, Nelson "captará os clichês trágicos na construção de suas tragédias... As noções de destino, fatalidade, maldição, vingança. Elementos como o coro. Um certo clima, um certo ambiente. Ele retomará também certos temas: o incesto, o infanticídio". ${ }^{2}$ O que se observa, contudo, é uma contínua desfiguração e reinterpretação desses espectros, como podemos observar em Senhora dos afogados, peça escrita em 1947.

Nessa peça, incluída por Magaldi no rol das obras míticas, a matéria do drama se constitui no âmago das relaçōes familiares, nas quais os sentimentos malditos são o núcleo de todas as ações e conflitos. Em Senhora dos afogados, a casa dos Drummond, a famíliamatriz, é um cenário em ruínas. Margeada pelo mar, a casa é habitada pela atmosfera das mortes que, tanto no passado quanto no presente, arruinam as personagens. Imersa nesses ecos, a família Drummond sossobra. Em sua imanência de signo-coisa, mar e casa compõem um único ambiente plástico, como extensões metonímicas um do outro. Nessa superfície plana, epidérmica, flutuam, insepultos, os mortos fantasmáticos que assombram as placentárias relações familiares dos vivos.

Em torno do pai, Misael, assenta-se o núcleo familiar. Um cadáver do passado institui, na fabulação, o enigma que move uma das faces do enredo. Há dezenove anos, a amante de Misael fora morta, no dia mesmo em que o juiz celebrava suas bodas com Eduarda. A esse crime do passado vêm somar-se as mortes repentinas e inusitadas, no presente, de duas filhas do casal: Dora e Clara. A peça se abre com o velório de Clara, cujo corpo (como o de Dora) perdeu-se no mar:

(Superposição de dois ambientes: casa dos Drummond e café de cais. Na casa dos Drummond, mãe (D. Eduarda) e filha (Moema). D. Eduarda ainda formosa, apesar

\footnotetext{
'MAGALDI. Nelson Rodrigues: dramaturgia e encenaçōes, p.30-1.

${ }^{2}$ LOPES. Nelson Rodrigues: trágico, então moderno, p.94.
} 
de alguns cabelos grisalhos, casta e severa no seu luto fechado. Moema também de luto - e sem pintura como D. Eduarda. Ambas de uma palidez quase sobrenatural. Mãe e filha estão em pé, rígidas, hieráticas,. Nenhuma semelhança especial entre as duas. Mas os seus movimentos de mãos coincidem muito; e isso as exaspera. Esta coincidência será umas das constantes da peça. A avó (D. Marianinha) anda de um lado para outro, numa excitação de doente. É a doida da família. Nas paredes, retratos a óleo dos antepassados. Em cena, também, os vizinhos. São figuras espectrais. Um farol remoto cria, na família, a obsessão da sombra e da luz. Há também um personagem invisível: o mar próximo e profético, que parece estar sempre chamando os Drummond, sobretudo as suas mulheres. Moema tem um rosto taciturno, inescrutável, de máscara.) ${ }^{3}$

O cadáver do passado, infiltrado no presente, constitui, no âmbito da fábula, o enigma primeiro, em torno do pai, Misael, suspeito do assassinato da amante. Essa trama, por sua vez, recobre um outro veio de suspense, que lhe é subliminar: a misteriosa morte das filhas, sob a qual se esconde um conflito mais denso e paradigmático - o de Moema. $\mathrm{Na}$ ação condensada em um único dia, Nelson enreda dois enigmas, de tramas e motivaçōes diferenciadas, cruzando-os na resolução final que prenuncia a catástrofe familiar.

Ainda uma vez, o dramaturgo utiliza o vigoroso recurso da concentração. Excetuado o segundo quadro do terceiro ato, que funciona como epílogo, tudo acontece na tragédia num só dia: o anúncio da morte de Clarinha marca o início sombrio da ação. Era o 19. aniversário do casamento de D. Eduarda e Misael, celebrado no mesmo dia em que mataram a prostituta (e que se saberá ter sido assassinada por Misael). Nesse mesmo dia, oferecem um banquete a Misael, em desagravo pela suspeita de que seria ele o criminoso, quando, na verdade, ele foi. Ainda nesse mesmo dia, sem que se insinue um mínimo de inverosimilhança, D. Eduarda foge com o noivo da filha Moema, e o filho Paulo mata o sedutor. Em continuação, Misael amputa as māos da mulher, que morre. O quadro final da peça começa quando saiu o enterro de D. Eduarda e novas mortes completam as anteriores. Por uma réplica de Misael, sabe-se que é o dia seguinte, e nele morrem sua mãe louca, a quem Moema esqueceu de dar comida; Paulo que, por não poder viver mais, foge no caminho do mar, com a mesma sugestão de suicídio que vitimou Orin, em Electra Enlutada; e finalmente o próprio Misael, que tomba talvez por exaustão, por ataque cardíaco ou ímpeto de autodestruir-se. Resta Moema sozinha no palco, num diálogo silencioso de ódio com as própria mãos, evocando o desfecho de O'Neil, em que Lavínia se encerra solitária em casa. ${ }^{4}$

O eixo primeiro institui a falha paterna, o crime de Misael, e uma lógica temporal e causal transparente: os atos do passado transtornam e arruinam o presente com efeitos de aniquilamento progressivos. $O$ segredo da autoria desse crime é um saber público corrente, velado e desvelado pelas falas do coro de vizinhos e, finalmente, exposto pelo noivo que, por sua vez, revela-se filho de Misael com a prostituta assassinada:

Vizinho - Porque o Sr. Ministro precisava ser desagravado dessa calúnia - pois é uma calúnia - que, inclusive, deve ter chegado ao conhecimento de VV. SS. ...

D. EDUARDA - Não!

VIZINHO - ... calúnia que é assacada impiedosamente contra o marido de V. Excia. (...)

VıZINHO (num adendo) - ... por inimigos anônimos

\footnotetext{
${ }^{3}$ RoDrigues. Teatro completo, p. 259.

${ }^{4}$ Magaldi in Rodrigues. Teatro completo, p.41-2.
} 
VIZINHO - Inimigos anônimos, diz muito bem. Inimigos que não trepidam em apontar o Dr. Misael como o matador - imaginem - de uma moça de má fama...5

Misael (acobardado) - Meu filho morreu.

Nolvo (enfurecido) - Não. Minha mãe te disse que o filho morrera, porque eu não podia ser um Drummond ... Pareço morto? Minha mãe escreveu uma carta na véspera de morrer - escreveu que tu querias matá-la ... Confessa agora para mim e para tua mulher ...

MISAEL - Não!

Nolvo - ... confessa - mataste? (...)

Misael (ofegante) - Matei. ${ }^{6}$

O segundo enigma, centrado em Moema, cruza-se com a trama policialesca do primeiro eixo, mas a atravessa e ultrapassa, configurando a ação, o conflito e a temporalidade no universo de uma outra lógica, a do inconsciente, não aprisionável na cronologia da estória de Misael. Por amor ao pai, Moema matara as irmās, para entronarse única, nos afetos paternos:

Moema - Afoguei minhas irmãs, como se ferisse no meu próprio ser... Afoguei as filhas que preferias e acariciavas, enquanto eu sofria na minha solidão...

MISAEL (desesperado) - Elas não te fizeram nenhum mal. E por que as odiaste?

Moema (no seu ódio) - Tiraram todo o amor que eu teria de ti. Receberam as carícias que eu não tive... Elas descalçavam e acariciavam os teus pés... E eu, não! Era preciso que deixassem este mundo (...).

Moema - Procura em toda a casa, nos espelhos também... Tuas filhas não estarão em lugar nenhum... Nem vivas, nem mortas... Não existem nem os retratos, que eu destruí; nem as roupas... Queimei a memória delas... Sabes ainda como eram? Te lembra dos olhos, dos cabelos?

Misael - Talvez...

Moema - Sabes pouco... Saberás cada vez menos... Até que um dia nada restará delas na tua memória... Só existirei eu, minha imagem diante de ti... (apaixonadamente) Somos assassinos, pai, tu e eu!?

$\mathrm{Na}$ arquitetura dramática, a constatação do crime do pai apenas reifica a verdade recorrente, indiscretamente velada, mas reconhecível nas cenas que a tornam, paradoxalmente, visível. Já os crimes de Moema e as mortes que a personagem induz, tornam-se transparentes às suas motivações manifestas, introduzem uma revelação que à própria personagem se oculta, a da fatalidade do desejo. À medida que força as ações que desencadeiam a morte da mãe, dos irmãos, da avó e do próprio pai, Moema faz desabar sobre si mesma a sua própria catástrofe e a fatalidade singular que a elide dos outros membros da família, numa reviravolta inesperada do drama. Moema pensa que sabe, mas em verdade ignora-se, pois desconhece na própria demanda de amor a natureza abissal e paralisante dos desejos que, à sua revelia, nela agem. Essa diferença fundamental na natureza dos erros das personagens, estruturante da tragicidade do desfecho, encontra equivalência no destino diverso de Misael e de Moema. E é na construção desse destino que Nelson reconfigura, no âmbito da tragédia, a falha trágica e a fatalidade daí decorrente.

\footnotetext{
${ }^{5}$ Rodrigues. Teatro completo, p.265. Ato 1.

${ }^{6}$ IBIDEM. p.297-8. Ato 2.

7 IBIDEM. p.304-5. Ato 2.
} 
O crime do pai constitui uma falha de caráter que demanda uma resolução ética, na vingança tramada pelo filho ignorado. Um erro de caráter, pessoal e intransferível, cometido no passado, esparge-se pelo presente, ao encontro do erro de Moema, só assim precipitando sobre todos os seus efeitos funestos. Nesse sentido, Nelson produz uma "espécie de reviravolta das expectativas, uma desconstrução do clichê - o que parecia ser obra do destino não passava do fruto de uma paixão... Mas, a paixão se liga, freqüentemente, à fatalidade". 8 Os crimes de Moema, por outro lado, vazam o tecido ético e criam uma reviravolta mais contundente e significativa, de um apelo dramático mais perturbador, pois a falta se institui num lugar alheio ao poder de vontade do sujeito, como uma força que o pulsiona para um mais-além da razão. A falha de Moema fundase no âmbito do desejo que a submete à inconsciência determinante de sua tragicidade $\mathrm{e}$ de sua falta de liberdade, regendo, à revelia de seu poder de vontade, as suas ações. Enquanto Misael desfruta de liberdade suficiente para agir e refletir sobre seu comportamento, Moema, na peça, é a que deveras sofre di hamartiantiná, a falha trágica, deslocada por Nelson do âmago externo da intervenção divina para a cena íntima e interior da inconsciência puramente humana. Assim, enquanto o erro do pai é contingente e nos remete a um ato de vontade pessoal, a falha de Moema é estruturante e fatal. Por isso sua angústia, como a de Antígona, é tão devastadora. Entremortes, Moema sobrevive à queda de Misael, e esta a ruína de sua predestinada relação com o pai. A lógica que define os atos do pai é temporal, consciente, social, tópica e particular; a de Moema atemporal, inconsciente, subjetiva, paradigmática e universal.

Reconhecendo-se como assassino, e conhecendo os crimes da filha, Misael pode, ainda, escolher sua participação nos atos que sucedem a essa revelação, refletindo, a posteriori, sobre a trama em que se enredara:

MiSAel - De tudo... Culpada de tudo... Eu não teria feito o que fiz... Teria perdoado tua mãe... Os velhos perdoam... Tu me disseste para castigá-la aqui. (indica as próprias mãos) Eu te obedeci, Moema, fiz o que mandaste, e sem ódio, com um ódio que não era meu, era teu... (...) Eu teria perdoado, juro, Deus é testemunha...9

Aniquilado pelo infortúnio, Misael morre. Sua morte distende e alivia seu sofrimento. A sobrevida de Moema e a constatação de sua solidão perpetuam o seu castigo. Todas as mortes que precipitara só fazem interditar a realização do desejo de estar com o pai, já que este, abatido pelos próprios erros, sucumbe, deixando vazio o lekhos desejado. A queda abissal, por fim, não é a do pai, redimido na morte, mas a da filha, Moema, desamparada da possibilidade de ser com o outro, ali onde o outro já não está:

MOema - Expulsei-a do espelho... Foi-se embora... Não voltará nunca mais...

(No seu deslumbramento olha para o alto e não sente que o pai morreu, não vê que o que está no seu regaço é a cabeça de um pai morto.) (Curva-se para beijar o rosto de Misael e só então observa que ele morreu.)

Moema - (aterrada) - Pai... (duvida de si mesma) Não... não... (começa a aceitar a verdade) Não me deixes só... Não quero ficar só... (traz a cabeça de Misael para perto do rosto. Interpela o rosto e os olhos fixos de Misael) Morto... Não quero que te feches em tua morte... (pousa a cabeça de Misael no chão, e, sempre com medo,

${ }^{8}$ LOPES. Nelson Rodrigues: trágico, então moderno, p.95.

${ }^{9}$ Rodrugues. Teatro completo, p.329. Ato 3. 
vira-se rápida e corre para o espelho. Mas este não reflete a sua imagem, nem a de ninguém. $)^{10}$

Sobram, a Moema, o silêncio de uma imagem despida de todos os índices de identificação e a consciência repentina de sua própria outridade, constituída por uma falta significante, trágico destino do humano.

Nesse movimento desfigurante da hamartia grega, Nelson faz coincidirem em Moema as categorias da dor e do sofrimento que, para Kierkegaard, diferenciam a tragédia clássica do drama moderno. Para o filósofo, na tragédia antiga, a dor é mais profunda e menor o sofrimento, enquanto na tragédia moderna, o sofrimento é mais agudo e menos intensa a dor. ${ }^{11}$ Segundo Steiner, essa diferenciação é dependente, em Kierkegaard, do conceito e da manifestação da culpa trágica:

A dor grega é "tão doce e tão funda" porque lhe falta a consciência de si, a compreensão reflexiva da culpa. É uma dor que se derrama sobre o padecer do herói predestinado e em erro. Se há ambigüidade neste padecimento, se há opacidade (...) estas são de ordem estética. Na tragédia moderna, pelo contrário, a concepção da culpa é declarada e pessoal. Prevalece uma transparência implacável (...). Não é a dor, mas o sofrimento o que domina a nossa resposta. ${ }^{12}$

Para Kierkegaard, a mistura dialética da culpa e da inocência, da aparência e da opacidade, da dor e do sofrimento, cria um modo peculiar de compreensão da ambivalência trágica:

A verdadeira dor trágica exige conseqüentemente um elemento de culpa, o verdadeiro sofrimento trágico um elemento de inocência; a verdadeira dor trágica exige um elemento de transparência, o verdadeiro sofrimento trágico um elemento de obscuridade. ${ }^{13}$

Uma combinatória similar realiza-se em Senhora dos afogados, traduzida em Moema pela incidência de uma falha trágica que se constitui nos entremeios de luzes e sombras, inocência e culpa, reflexão e ignorância, vontade e desejo. Essa oscilação entre zonas de transparência e de opacidade insiste também no âmbito da linguagem. Não existe comunicação possível entre Moema e as outras personagens dramatizadas no texto, à medida que as realidades evocadas pelas falas nos remetem a níveis de significância não conciliáveis. Enquanto o discurso paterno, as falas do noivo e de Paulo adquirem uma transparência imediata, reificando um saber público, também manifesto na aparição fantasmática da amante morta, a linguagem de Moema, da avó e de algumas intervenções dos coros produzem zonas obscuras de significância, forçando a ambivalência do dito que se insere no código enigmático e poético do vaticínio:

Vizinhos (em conjunto) - Primeiro Dora, depois Clarinha!

VIZINHO (solista, para um e outro) - Já duas afogadas na família!

Avó - Depois das mulheres, será a vez dos homens...

VIZINHO (solista) - Acredito!

\footnotetext{
${ }^{10}$ Rodrigues. Teatro completo, p.331. Ato 3.

"Cf. KierkegaARD. Estudios esteticos II.

${ }^{12}$ Steiner. Antígonas, p.77.

${ }^{13}$ Kierkegaard citado por Steiner. Antígonas, p.78.
} 
Avó - E depois de não existir mais a família - a casa! (Olha em torno as paredes, os móveis, a escada, o teto) Então, o mar virá aqui, levará a casa, os retratos, os espelhos! ${ }^{14}$

Avó - O que importa é que és a filha única... só tu existes...

MoEma (com expressāo de triunfo) - Só eu existo!

Avó - Nenhuma outra filha, nenhuma outra irmã.

MOEMA - Só eu.

Avó - És filha única, mas não a única mulher...

MoEma (elevando a voz, com espanto) - Não sou a única mulher... Nesta casa, não sou a única mulher...

Avó - Existe outra. Não eu, que sou velha e doida...

MOEMA - Não tu, que és velha e doida. Outra mulher, outra mulher, outra mulher... ${ }^{15}$

Em diversos momentos dos diálogos, o discurso profético é prospectivo e aponta para uma possível conotação no devir, a ruína da família, na fala da avó, a morte de Eduarda (a outra mulher), na elocução de Moema. O futuro é pressentido quer em sua inexorabilidade, quer em sua necessidade. Já as falas de Misael convergem para o passado, num movimento de retrospecção quase puramente denotativo, que repete o saber comum:

Misael (já de pé) - Quando me levantei para falar, para fazer o discurso - vi uma mulher... Estava no outro lado da mesa, bem na minha frente... vestida diferente das outras - e sem pintura...

Moema (com um princípio de medo) - Era uma convidada!

MISAEl - Convidada? (numa tensão inexplicável) Não, não podia ser convidada... (...) Eduarda, eu vi essa mulher o tempo todo. (gula) Mas eu sabia que ela tinha morrido há muitos anos... (...) Não podia estar ali, mas estava; ninguém a via, só eu... Então, não pude continuar; parei o discurso no meio... Fugi... Ela também saiu, veio comigo... (...) Deve estar aqui me acompanhando... ${ }^{16}$

O modo como Nelson, nesta peça, faz coincidirem, por um lado, o tom lírico e profético da linguagem com a lógica oculta do desejo de Moema; e, por outro, a construção denotativa e transparente com o desvelamento progressivo do crime de Misael, reduplica as ordens de sentido que emprega na composição diferenciada do caráter de Misael e das compulsões de Moema, reificando, nele, a transitoriedade e a contingência e, nela, a eternidade e a permanência. Nesse movimento, Nelson realiza, no ideal dramático, "o ideal da acção total do discurso; o de um mundo totalmente dito", bastando-nos, como no drama grego, "escutar para ouvirmos essas outras ordens de sentido e de experiência possíveis que incidem na linguagem, que a linguagem conota, quando o discurso se liberta de sujeições à (pretensa) acção". ${ }^{17}$

Se, no trágico grego, a falha primordial constitui-se no âmbito do desígnio divino - que, vertiginosamente, derrama-se sobre a polis, no ato mesmo que aos deuses se oferece - , no drama rodriguiano o ato teatral instala-se na zona sombreada dos afetos, na qual o cenário divino cede lugar à cena, agora trágica, do inconsciente. Afinal, só em seu desamparo, entremortes, a Moema só resta um gozo póstumo. Num texto dramático

\footnotetext{
${ }^{14}$ Rodrigues. Teatro completo, p.262. Ato 1.

${ }^{15}$ IBIDEM. p.279. Ato 1.

${ }^{16}$ IBIDEM. p.276. Ato 1.

${ }^{17}$ Sterner. Antígonas, p.276-7.
} 
em que os diálogos parecem nos evocar muitas vezes uma insistente meditação sobre a subjetividade, Nelson Rodrigues, na ausência dos deuses, arautos de nossos destinos, faz recair sobre sua protagonista uma fatalidade quiçá mais tenebrosa: a do desejo - o que, afinal, como humanos, nos resta.

\section{A}

\section{ABSTRACT}

In this essay, I underline the reconfiguration of the hamartia's notion, the tragic error, in Nelson Rodrigues' Senhora dos afogados, focusing my attention on the character Moema.

KEY WORDS

hamartia, fatality, Senhora dos afogados

\section{REFERENCIAS BIBLIOGRÁFICAS}

KierkegaARD, Sören. Estudios esteticos II, de la tragedia y otros ensayos. Madrid: Ediciones Guadarrama, 1969.

LOPES, Ângela Leite. Nelson Rodrigues: trágico, então moderno. Rio de Janeiro: Ed. UFRJ/Tempo Brasileiro, 1993.

Magaldi, Sábato. Nelson Rodrigues: dramaturgia e encenaçōes. Sāo Paulo: Perspectiva/Edusp, 1987.

Rodrigues, Nelson. Teatro Completo. v.2. Org. e introd. Sábato Magaldi. Rio de Janeiro: Nova Fronteira, 1981.

Steiner, George. Antigonas. Trad. de Miguel Serras Pereira. Lisboa: Antropos, 1995. 